in vivo $34: 2507-2516(2020)$

doi:10.21873/invivo.12067

\title{
Hydrogen Sulphide and Nitric Oxide Cooperate in Cardioprotection Against Ischemia/Reperfusion Injury in Isolated Rat Heart
}

\author{
SAVAS USTUNOVA $^{1}$, SELCUK TAKIR $^{2}$, NADIM YILMAZER ${ }^{3}$, HURI BULUT $^{4}$, DIDEM ALTINDIREK ${ }^{5}$, \\ OZDEN HATIRNAZ NG ${ }^{6}$, CIHAN DEMIRCI TANSEL $^{7}$, B. SONMEZ UYDES DOGAN ${ }^{8}$, \\ UGUR OZBEK $^{9}$, ELIF ILKAY ARMUTAK ${ }^{10}$ and EBRU GUREL GUREVIN ${ }^{7}$ \\ ${ }^{1}$ Department of Physiology, School of Medicine, Bezmialem Vakif University, Istanbul, Turkey; \\ ${ }^{2}$ Department of Medical Pharmacology, School of Medicine, Giresun University, Giresun, Turkey; \\ ${ }^{3}$ Department of Biology, Faculty of Arts and Sciences, Namik Kemal University, Tekirdag, Turkey; \\ ${ }^{4}$ Department of Medical Biochemistry, School of Medicine, Istinye University, Istanbul, Turkey; \\ ${ }^{5}$ Department of Genetics, Aziz, Sancar Institute of Experimental Medicine, Istanbul University, Istanbul, Turkey; \\ ${ }^{6}$ Department of Medical Biology, School of Medicine, Acibadem Mehmet Ali Aydinlar University, Istanbul, Turkey; \\ ${ }^{7}$ Department of Biology, Faculty of Science, Istanbul University, Istanbul, Turkey; \\ ${ }^{8}$ Department of Pharmacology, Faculty of Pharmacy, Istanbul University, Istanbul, Turkey; \\ ${ }^{9}$ Department of Medical Genetics, School of Medicine, Acibadem Mehmet Ali Aydinlar University, Istanbul, Turkey; \\ ${ }^{10}$ Department of Histology and Embryology, Faculty of Veterinary Medicine, \\ Istanbul University-Cerrahpasa, Istanbul, Turkey
}

\begin{abstract}
Background/Aim: This study was designed to provide further evidence for the interactions between hydrogen sulfide $\left(\mathrm{H}_{2} \mathrm{~S}\right)$ and nitric oxide (NO) in ischemia/reperfusion (I/R) injury. Materials and Methods: Rat hearts were studied with the Langendorff technique using the $\mathrm{H}_{2} \mathrm{~S}$ donor sodium hydrosulfide (NaHS, $\left.40 \mu \mathrm{M}\right)$ and the cystathionine gamma-lyase (CTH or CSE) inhibitor DLpropargylglycine (PAG, $1 \mathrm{mM})$. NO synthase inhibitor $L-N G$ nitroarginine methyl ester ( $L-N A M E, 30 \mathrm{mg} / \mathrm{kg}, 7$ days) was administered before the isolation. The hearts were homogenized for biochemical and molecular analysis. Results: NaHS reversed I/R-induced cardiac performance impairment, increased tissue nitric oxide production and decreased tissue markers for cardiac injury, while L-NAME inhibited these effects. The expression of CTH was increased with PAG, which was suppressed by L-NAME. Conclusion:
\end{abstract}

This article is freely accessible online.

Correspondence to: Savas Ustunova, Ph.D., Department of Physiology, School of Medicine, Bezmialem Vakif University, 34093 Istanbul, Turkey. Tel: +90 5335106592, e-mail: sustunova@bezmialem.edu.tr

Key Words: Hydrogen sulfide, nitric oxide, isolated heart, ischemia/reperfusion injury, oxidative damage.
$\mathrm{H}_{2} \mathrm{~S}$ and $\mathrm{NO}$ increase each other's production suggesting their interaction and cooperation in cardioprotection against $I / R$ injury.

Nitric oxide (NO), carbon monoxide (CO), and hydrogen sulfide $\left(\mathrm{H}_{2} \mathrm{~S}\right)$, in the order of their discovery, are gasotransmitters, a term that refers to a gaseous transmitter, and was first coined by Wang (1). All are endogenously produced small signaling molecules with low molecular weight (NO, $30 \mathrm{Da}$; CO, $28 \mathrm{Da} ; \mathrm{H}_{2} \mathrm{~S}, 34 \mathrm{Da}$ ). Because they are small gaseous molecules, they reach easily their intracellular targets to activate them, by diffusing freely across the plasma membrane. They play a pivotal roles in the control of many physiological functions, including regulation of cardiovascular, nervous, gastrointestinal, excretory, immune, and reproductive systems (2-5). Of these three gaseous transmitters, $\mathrm{H}_{2} \mathrm{~S}$ that was first introduced as a metabolic product in mammals by the American biochemist Vincent $\mathrm{Du}$ Vigneaud, has gained much attention in recent years due to its involvement in the above-mentioned physiological functions $(2,6,7)$. It is endogenously synthesized in most mammalian tissues from L-cysteine and/or L-homocysteine by cystathionine beta-synthase (CBS), cystathionine gamma-lyase (CTH or CSE), and cysteine aminotransferase together with 3-mercaptopyruvate sulfurtransferase $(2,4,8)$.

Heart failure, the major health issue in the world and the leading cause of deaths, is a complicated disease caused by 


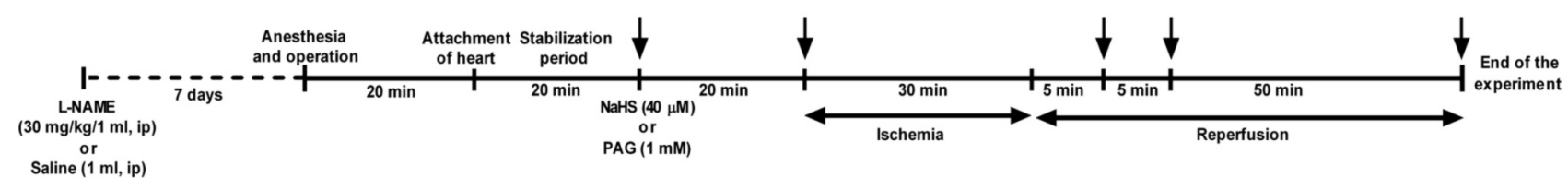

Figure 1. Experimental design ( $\downarrow$ : time points for cardiodynamic analyses).

a variety of common stresses to the heart, such as hypertension, diabetes, and myocardial infarction that is the result of ischemic heart disease $(9,10)$. Therefore, novel complementary compounds that are safe and effective alternatives to conventional pharmacotherapy of heart failure are needed. In recent years, a considerable number of studies have revealed that $\mathrm{H}_{2} \mathrm{~S}$ plays important roles in alleviating ischemia/reperfusion (I/R) injury (11), and that plasma sulfur concentration is inversely proportional to the severity of congestive heart failure (12). In addition, exogenous administration of $\mathrm{H}_{2} \mathrm{~S}$ or cardiac-specific CTH overexpression provides protection against acute myocardial $\mathrm{I} / \mathrm{R}$ injury and heart failure $(10,12,13)$.

Since 1997, when the first experimental study by Hosoki, et al. (14) revealed that endogenous $\mathrm{H}_{2} \mathrm{~S}$ may regulate smooth muscle tone in synergy with $\mathrm{NO}$, many studies have provided strong and growing evidence that these two molecules could modulate each other's activities by altering the functions of the related proteins (15-17). Kondo, et al. (18) has shown that $\mathrm{H}_{2} \mathrm{~S}$ protected against heart failure via up-regulation of endothelial nitric oxide synthase (eNOS) activity, while a new thiol sensitive molecule resulted from the reaction of $\mathrm{H}_{2} \mathrm{~S}$ with NO was found to regulate heart function (19). However, the precise mechanisms of interactions between $\mathrm{NO}$ and $\mathrm{H}_{2} \mathrm{~S}$ that affect heart failure, and whether $\mathrm{H}_{2} \mathrm{~S}$ modulates the biological effects of NO are not entirely clear (8). Therefore, it is urgently needed to deeply understand the underlying mechanisms, so that novel strategies can be developed to provide protection against heart failure $(10,17)$.

In view of these facts, the present study aimed to provide further evidence for the effects of $\mathrm{H}_{2} \mathrm{~S}$ and $\mathrm{NO}$, and their interactions in $\mathrm{I} / \mathrm{R}$ injury by employing the Langendorff technique of isolated rat heart perfusion.

\section{Materials and Methods}

Animals. Forty-eight male Wistar albino rats weighing 250-300 g were used. They were housed under $12 / 12 \mathrm{~h}$ day/night cycle and controlled room temperature $\left(22 \pm 2^{\circ} \mathrm{C}\right)$ and were allowed free access to food and water, and received humane care according to the criteria outlined in the 'Guide for the Care and Use of Laboratory Animals (2011)' prepared by the National Academy of Science and published by the National Institutes of Health. Animal experiments were reviewed and approved by the Animal Care and Use Committee of Istanbul University.
Isolated heart perfusion. All Langendorff isolated heart studies were performed as previously described (20). Briefly, animals were anesthetized by intraperitoneal injection of $75 \mathrm{mg} / \mathrm{kg}$ pentobarbital sodium (Pental Sodyum, IE Ulagay, Istanbul, Turkey). Tracheotomy was performed, and mechanical ventilation (Small Animal Ventilator Model 683, Harvard Apparatus, Holliston, MA, USA) was initiated soon after surgical opening of the thorax. Heparin (150 IU) was administered from the abdominal vein, and before excision of the heart the aorta was cannulated in situ. The hearts were then Langendorff-perfused at $37^{\circ} \mathrm{C}$ with Krebs-Henseleit buffer containing (mM) $118 \mathrm{NaCl}, 0.5$ EDTA, $4.7 \mathrm{KCl}, 2.25 \mathrm{CaCl}_{2}, 1.2 \mathrm{MgSO}_{4}, 25$ $\mathrm{NaHCO}_{3}, 1.2 \mathrm{KH}_{2} \mathrm{PO}_{4}$, and 11 glucose, 1 lactate, 0.5 glutamine, and 0.1 pyruvate, gassed with $95 \% \mathrm{O}_{2}-5 \% \mathrm{CO}_{2}$. End-diastolic pressure was adjusted at $5-10 \mathrm{mmHg}$. The hearts were perfused by a mini pulse peristaltic pump (ML172B, ADInstruments, Sydney, Australia) at a constant flow with initial perfusion pressure of approximately 80 $\mathrm{mmHg}$. After stabilization of pressure development during the first 20 min of Langendorff-perfusion, 6 groups of hearts, each composed of 8 animals, were studied (Figure 1). All hearts were subjected to 30 min ischemia and $60 \mathrm{~min}$ reperfusion by switching the peristaltic pump off and on. The ischemia/reperfusion (IR) group was just perfused with Krebs-Henseleit solution for $20 \mathrm{~min}$, while the sodium hydrosulphide (NaHS) group was perfused with $40 \mu \mathrm{M}$ NaHS (as $\mathrm{H}_{2} \mathrm{~S}$ donor), and the DL-propargylglycine (PAG) group with $1 \mathrm{mM}$ PAG (as CTH inhibitor) prior to ischemia. L-NG-Nitroarginine methyl ester (L-NAME), L-NAME+NaHS, and L-NAME+PAG groups additionally received $30 \mathrm{mg} / \mathrm{kg}$ L-NAME (as NOS inhibitor) intraperitoneally for 7 days before Langendorff studies.

Cardiodynamic analysis. Left ventricular pressure was recorded by means of a balloon catheter placed inside the left ventricle and connected to a physiological pressure transducer (MLT844, ADInstruments) for assessment of contractile performance, while a second physiological pressure transducer was connected to the system in order to record the perfusion pressure via the data acquisition unit (PowerLab ML870B2, ADInstruments). The obtained data were analyzed with an appropriate software (LabChart 7; ADInstruments), and the records at certain time points $\left[0^{\text {th }} \mathrm{min}\right.$ : end of stabilization (baseline), $20^{\text {th }}$ min: end of drug administration before ischemia; $55^{\text {th }} \mathrm{min}: 5^{\text {th }}$ min of reperfusion, $60^{\text {th }} \mathrm{min}$ : $10^{\text {th }} \mathrm{min}$ of reperfusion, $110^{\text {th }} \mathrm{min}$ : end of experiment] were used for further analyses of cardiac parameters, including end diastolic pressure (EDP), left ventricular developed pressure (LVDP), Max dP/dt (a specific index used to determine the ability of the heart to contract), and rate pressure product (RPP, an indirect index of myocardial oxygen consumption and cardiac function).

Biochemical analysis. At the end of the experiment, the hearts were homogenized with a teflon piston homogenizer (Sartorius Potter S, Goettingen, Germany) in ice-cold PBS (pH 7.4) in a borosilicate 
Ustunova et al: Hydrogen Sulphide and Nitric Oxide Cooperate in Cardioprotection

Table I. Primer sequences and universal probe numbers for gene expression analysis.

\begin{tabular}{lccr}
\hline Gene & Primer forward (5'-3') & Primer reverse (5'-3') & Universal Probe No \\
\hline$i N O S$ & GACCAGAGGACCCAGAGACA & ATTCAATGGCTTGAGGCAGA & 25 \\
CNOS & TGACCCTCACCGATACAACA & CGGGTGTCTAGATCCATGC & 5 \\
\hline
\end{tabular}

glassware of $15 \mathrm{ml}$. The homogenate was centrifuged at $15.000 \times g$ at $4^{\circ} \mathrm{C}$ for $20 \mathrm{~min}$.

As tissue markers for cardiac injury, the levels of creatine kinaseMB (CK-MB) (Uscn Life Science Inc., Wuhan, PR China), a marker of myocardial injury, lactate dehydrogenase (LDH) (Elabscience, Wuhan, PR China), a marker of necrosis, and glutathione peroxidase (GPx) (Elabscience), an endogenous antioxidant enzyme, were measured in supernatant by ELISA. The production of $\mathrm{NO}$ and $\mathrm{H}_{2} \mathrm{~S}$ was measured with a nitrate/nitrite assay kit (Cayman Chemical, Ann Arbor, MI, USA), and a $\mathrm{H}_{2} \mathrm{~S}$ ELISA kit (Elabscience), respectively.

\section{Gene expression analysis}

Homogenization and RNA isolation. Total RNA was isolated from cardiac tissue via TRIzol ${ }^{\circledR}$ Reagent (Invitrogen-Thermo Fisher Scientific, Waltham, MA, USA) as described in the manufacturer's protocol. Briefly, $0.1 \mathrm{~g}$ of tissue was thawed, and homogenized in $1 \mathrm{ml} \mathrm{TRIzol}{ }^{\circledR}$ Reagent with a benchtop homogenizer (MP Biomedicals LLC, CA, USA). Then, the resulting homogenate was incubated for $5 \mathrm{~min}$ at room temperature. After the addition of $200 \mu \mathrm{l}$ chloroform to each sample, they were incubated for 2-3 $\mathrm{min}$ at room temperature, and centrifuged for $15 \mathrm{~min} 12.000 \times g$ at $4^{\circ} \mathrm{C}$, forming a lower red phenol-chloroform interphase and a colorless upper aqueous phase. The latter containing RNA was transferred to a new tube, and the former containing protein was stored at $-20^{\circ} \mathrm{C}$ for protein isolation. Precipitation of RNA was performed with the addition of $70 \%$ ethanol and incubation for $10 \mathrm{~min}$ at room temperature. The quality and quantity of RNA was measured by a spectrophotometer (Nanodrop ND-1000 spectrophotometer; Thermo Fisher Scientific, Waltham, MA, USA).

cDNA synthesis and real-time PCR. Random hexamers (pdN6) (Roche Applied Science, Mannheim, Germany) and M-MLV reverse transcriptase (Life Technologies, Carlsbad, CA, USA) were employed to synthesize cDNA from $1 \mu \mathrm{g}$ of total RNA. The obtained cDNA samples were kept at $-20^{\circ} \mathrm{C}$. eNOS, inducible nitric oxide synthase (iNOS), and CTH gene expression analysis was performed using a LightCycler 480 instrument (Roche Applied Science, Penzberg, Upper Bavaria, Germany). Gene-specific primers and probes were designed using Universal ProbeLibrary reference gene assays for mouse or rat (Universal Probe Library Rat-ACTB Gene Assay; Cat. No. 05046203 001, Roche Applied Science, Penzberg, Upper Bavaria, Germany) (Table I). The housekeeping gene ACTB ( $\beta$-actin) was used to standardize quantification in gene expression, by performing two-color real-time PCR. Based on the mathematical model described by Livak et al. (21), double delta $\mathrm{Ct}$ analysis was used to calculate relative gene expressions.
Statistical analysis. All data were statistically analyzed with GraphPad Prism 6.0 (GraphPad Prism Software, San Diego, CA, USA), and presented as mean \pm standard error of mean (mean \pm SEM). A value of $p<0.05$ was considered as statistically significant. Cardiodynamic results were evaluated by two-way analysis of variance (ANOVA), while gene expression and biochemical results were analyzed by one-way ANOVA and followed by post-hoc Bonferroni's multiple comparison test.

\section{Results}

Cardiodynamic results. The end diastolic pressure values were close to each other in all groups before ischemia, which increased them significantly $(p<0.001)$, implying diminished cardiac contractility that is observed in heart failure. Administration of L-NAME, NaHS or PAG induced a statistically significant $(p<0.01)$ decrease in EDP values. Following ischemia, the highest EDP value was determined at the $5^{\text {th }}$ min of reperfusion in the L-NAME+NaHS group, while the lowest value was in the groups of L-NAME and NaHS. At the end of reperfusion, values were approximated to those of the initial point in the groups of L-NAME and NaHS. It was interesting that perfusion with PAG alone reversed this effect and caused an increase in EDP values when compared to perfusion with NaHS alone (Figure 2A). As to values of LVDP, there was a significant decrease only in the NaHS group compared to the IR $(p<0.001)$ and L-NAME $(p<0.001)$ groups. The decrease observed due to ischemia at the $5^{\text {th }}$ min of reperfusion was found to be increased in the later stages of reperfusion in all groups. The highest value was observed in the L-NAME group, whereas the lowest value was in the IR group (Figure 2B). Max dP/dt values were also similar with the LVDP results (Figure 3A). Before ischemia, the initial RPP values of all groups were in parallel with each other except for the NaHS group. Following ischemia, the values in all groups decreased until the first $5^{\text {th }}$ min of reperfusion, and then increased with the progression of reperfusion. The best recovery occurred in L-NAME $(p<0.001)$, NaHS $(p<0.01)$, and L-NAME+PAG $(p<0.05)$ groups in descending order, whereas the lowest recovery was in the IR $(p<0.001)$ and L$\mathrm{NAME}+\mathrm{NaHS}(p<0.001)$ groups (Figure $3 \mathrm{~B})$.

Biochemical results. CK-MB levels showed a significant increase $(p<0.01)$ in the L-NAME+PAG group compared to the 

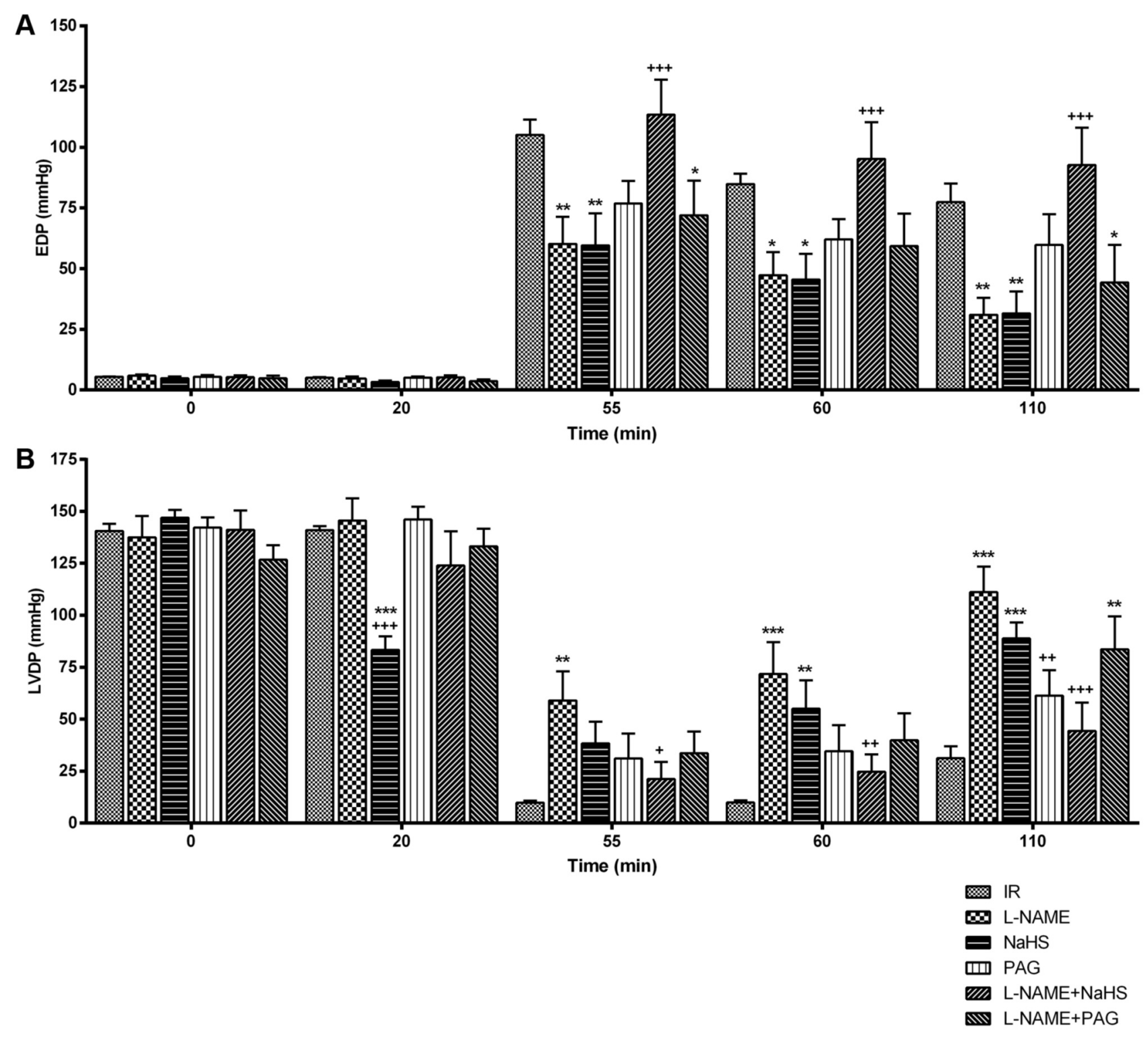

Figure 2. Cardiodynamic analysis. (A) The end diastolic pressure (EDP), B) Left ventricular developed pressure (LVDP) values of all groups. ${ }^{*} p<0.05,{ }^{*} p<0.01, * * * p<0.001$, statistical significance compared to the IR group; ${ }^{+} p<0.05,{ }^{++} p<0.01,{ }^{+++} p<0.001$, statistical significance compared to the L-NAME group.

IR group, while a significant decrease was observed in all other groups $(p<0.001)$ (Figure 4A). Apart from the L-NAME+PAG group $(p<0.001)$, all groups had decreased levels of LDH in comparison with both the IR and L-NAME groups (Figure 4B). NaHS and PAG administration increased the levels of GPx compared to both the IR and L-NAME groups $(p<0.001)$. In the L-NAME+NaHS group, the levels of this enzyme also increased compared to the IR group, while they significantly decreased in the L-NAME+PAG group (Figure 4C).

The levels of $\mathrm{H}_{2} \mathrm{~S}$ were increased by NaHS administration in the tissue compared to both the IR and L-NAME groups $(p<0.001)$, but PAG administration caused a decrease $(p<0.001)$. However, $\mathrm{H}_{2} \mathrm{~S}$ increased in the L-NAME and LNAME+NaHS groups $(p<0.001$ for both), whereas it decreased in the L-NAME+PAG group as in the PAG group $(p<0.001)$ (Figure 4D). NaHS administration led to an increase in NO levels $(p<0.001)$, but PAG administration did not cause a significant change. Nitrate/nitrite levels significantly decreased $(p<0.001)$ in all L-NAME-administered groups compared to the IR group. L-NAME+NaHS combination increased nitrate/nitrite levels $(p<0.05)$ compared to the L-NAME group, whereas PAG had no effect (Figure 4E). 

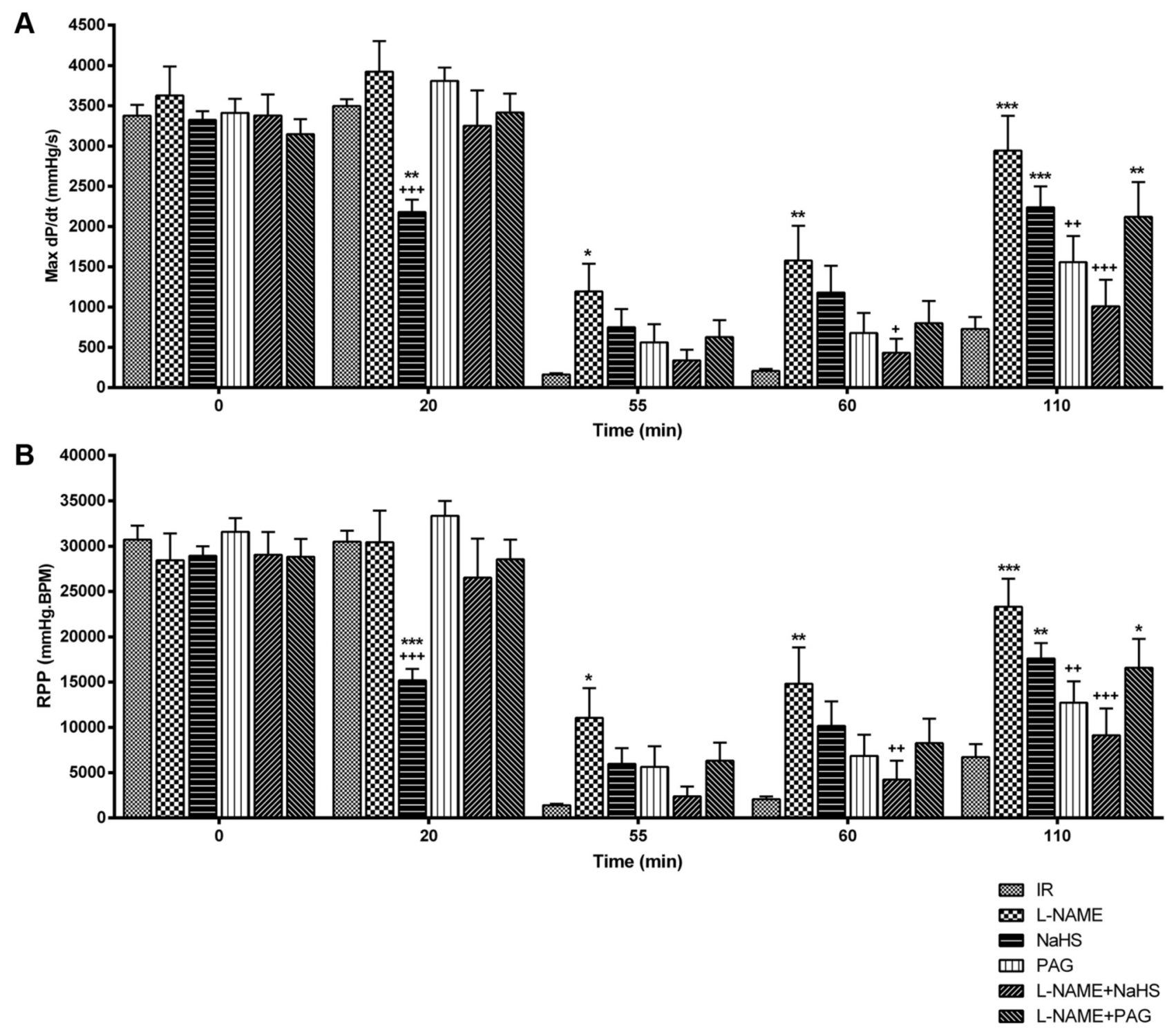

Figure 3. Cardiodynamic analysis. A) The Max dP/dt, B) Rate pressure product (RPP) values of all groups. $* p<0.05$, **p<0.01, ***p<0.001, statistical significance compared to the IR group; ${ }^{+} p<0.05,{ }^{++} p<0.01,{ }^{++} p<0.001$, statistical significance compared to the L-NAME group .

Gene expression results

eNOS, iNOS, and CTH mRNA expression. Relative mRNA expressions of genes were evaluated by RT-PCR analysis. The expression levels of eNOS mRNA were similar in all groups except for the NaHS-administered groups, in that NaHS administration caused a decrease in eNOS mRNA expression, while a further decrease was detected in the L-NAME+NaHS group. However, this decrease was not statistically significant (Figure 5A). L-NAME administration alone caused a prominent increase in the expression of iNOS mRNA, although it was not statistically significant. In contrast to the increment with L-NAME alone, the administration of NaHS and PAG with L-NAME resulted in a decrease (Figure 5B).
The expression profile of CTH was intriguingly different among all groups; although PAG increased its expression, LNAME administration suppressed it significantly $(p<0.01)$ in the PAG group. PAG co-administered with L-NAME showed a similar decrease with the L-NAME group (Figure 5C).

\section{Discussion}

A considerable number of studies have been performed to examine the cardioprotective effects of $\mathrm{H}_{2} \mathrm{~S}$ and $\mathrm{NO}$, and the interactions between them in $\mathrm{I} / \mathrm{R}$ injury, by employing several in vitro and in vivo experimental models of cardiac injury, including cultured cardiomyocytes, isolated perfused 

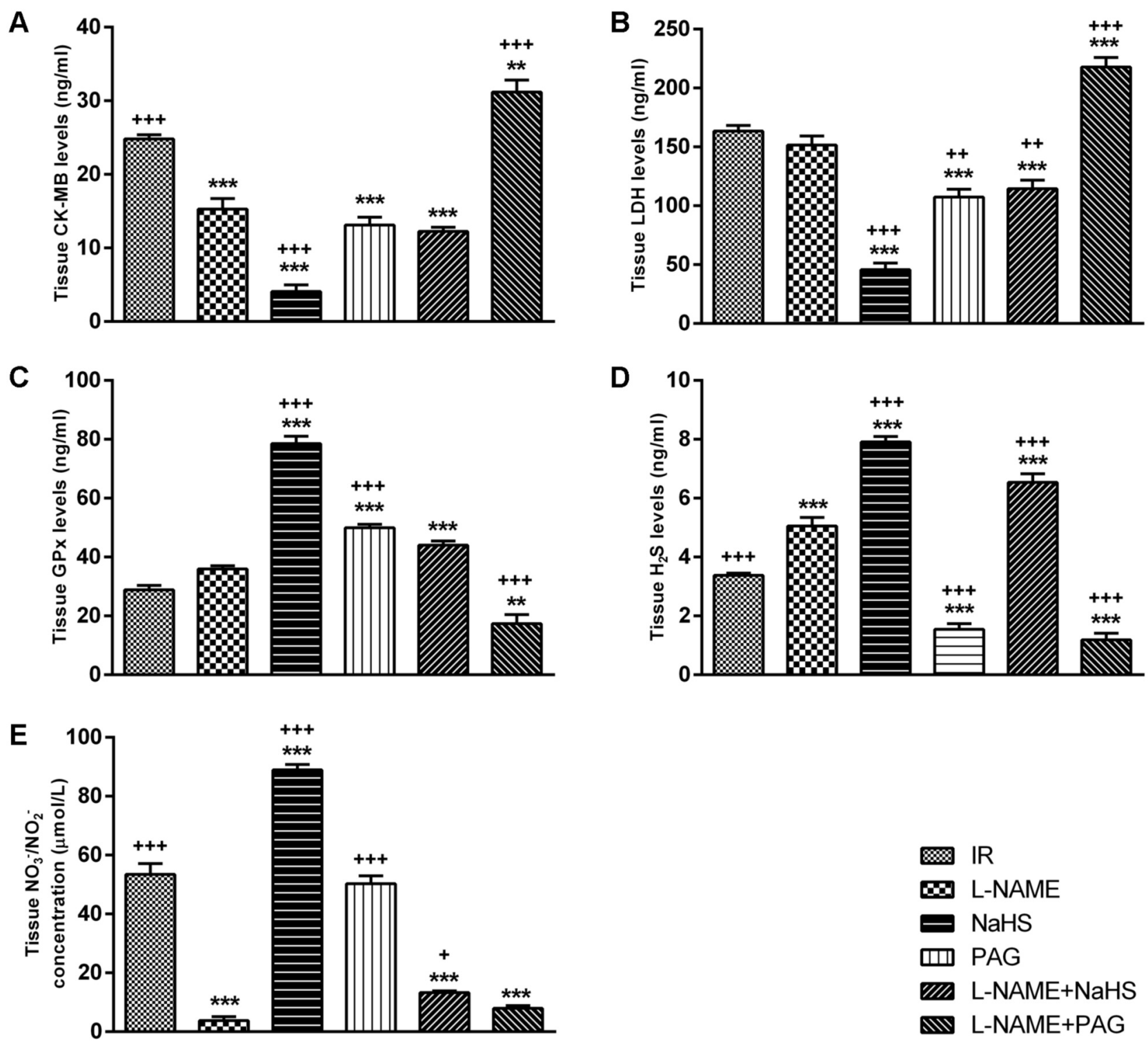

Figure 4. Biochemical analysis in heart tissue samples. A) $C K-M B, B) L D H, C) G P x, D) H_{2} S$ and E) Nitrate/nitrite levels of all groups. **p<0.01, $*_{* *}^{*} p<0.001$, statistical significance compared to the IR group $;{ }^{+} p<0.05,{ }^{++} p<0.01,{ }^{+++} p<0.001$, statistical significance compared to the L-NAME group.

hearts, and rodent and large animal (rabbit, dog, pig) models (17, 22-26). However, to the best of our knowledge, no study has examined the effect of NaHS, PAG and L-NAME on isolated rat heart administered, and the present study is the first to establish the role of these donors and inhibitors in cardioprotection against $\mathrm{I} / \mathrm{R}$ injury in rat heart.

The studies that aim to reveal the role of $\mathrm{H}_{2} \mathrm{~S}$ in physiological functions are generally based on two strategies: (i) inhibition of endogenous $\mathrm{H}_{2} \mathrm{~S}$, and (ii) administration of exogenous $\mathrm{H}_{2} \mathrm{~S}$ by employing NaHS as donor. Although the latter strategy is found inconvenient because the large and quick release of $\mathrm{H}_{2} \mathrm{~S}$ from $\mathrm{NaHS}$ may have detrimental effects on the experimental animals, this may be negligible since the resulting effects will be fairly short lasting (27). Similarly, the NO synthase inhibitor L-NAME is exogenously administered to the experimental animals in studies investigating the biological functions of NO. Accordingly, the experimental setup of our study is based on these strategies.

In our study, the EDP values that were decreased by ischemia, suggesting diminished cardiac contractility in heart failure, were restored to those of initial levels at the end of 
A

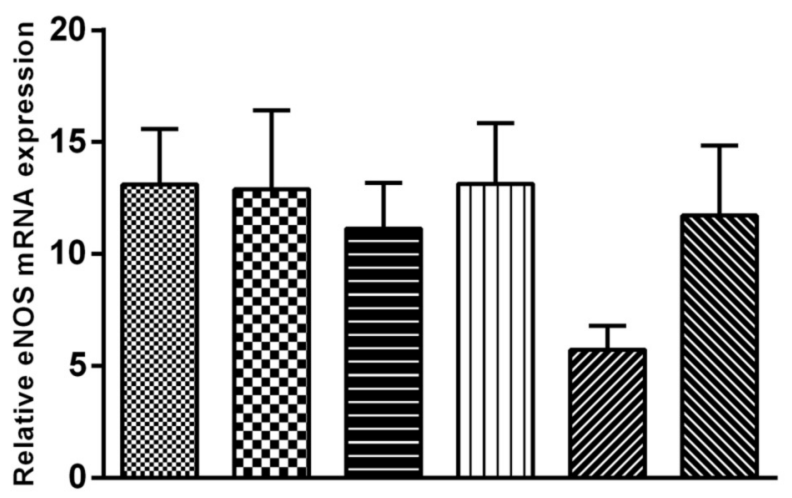

B

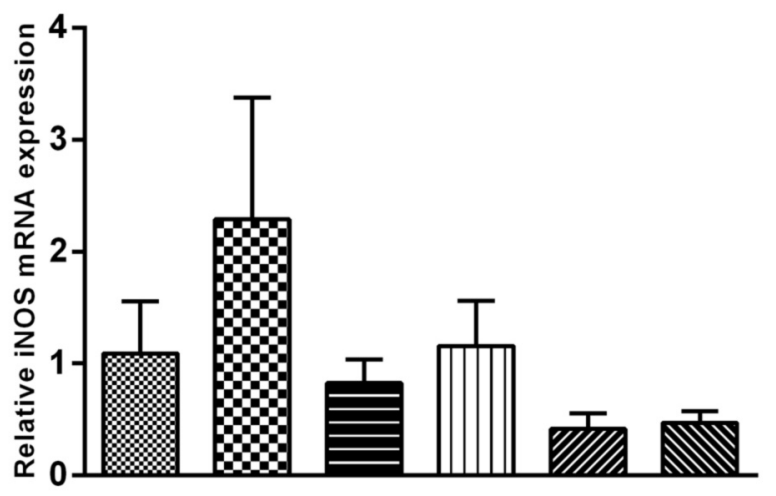

C

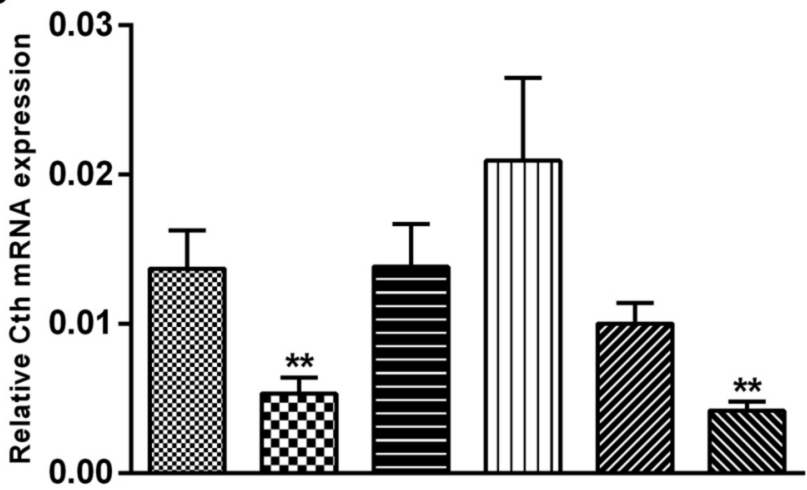

Figure 5. RT-PCR analysis in heart tissue samples. A) eNOS B) iNOS and C) Cth mRNA expressions. All expression levels were measured relative to $\beta$-actin by RT-PCR. **p<0.01, statistical significance compared to the PAG group.

reperfusion in the L-NAME and NaHS groups, while a significant decrease in Max $\mathrm{dP} / \mathrm{dt}$ and LVDP values was observed in the NaHS group. Concerning the RPP values, the best recovery was observed with the L-NAME, NaHS, and L-NAME+PAG. These results obviously show the role of both $\mathrm{H}_{2} \mathrm{~S}$ and $\mathrm{NO}$ in cardioprotection against I/R injury in rat heart, and are concordant with many studies. Johansen $e t$ al. (28) have shown that exogenous $\mathrm{H}_{2} \mathrm{~S}$ decreased left ventricular Max dP/dt in a concentration- and timedependent manner in rat heart. In a study performed in isolated rat hearts, NaHS administration led to a significant reduction in heart rate (HR) and LVDP, and this effect was ascribed to the muscle relaxant role of $\mathrm{H}_{2} \mathrm{~S}$, suggesting that it has a similar effect on myocardium (29). Moreover, postconditioning with $\mathrm{H}_{2} \mathrm{~S}$ improved the contractile and diastolic functions of the heart subjected to $\mathrm{I} / \mathrm{R}$, as revealed with improved HR, Max dP/dt, Min dP/dt, and LVDP, and reduced left ventricular EDP in the left atrium after reperfusion in the study in isolated rat hearts by Luan et al. (24). We obtained similar results in our isolated heart study, which suggests that a decrease in $\mathrm{H}_{2} \mathrm{~S}$ and $\mathrm{NO}$ levels due to the inhibition of synthesizing enzymes might be responsible for the impaired cardiac parameters in ischemia. It has been reported that cardioprotection by $\mathrm{H}_{2} \mathrm{~S}$ occurs in I/R injury through the inhibition of oxidation, increase in mitochondrial biogenesis, restoration of mitochondrial dysfunction, inhibition of heart cell apoptosis, reduction in the expression of proinflammatory cytokines and iNOS, up-regulation of eNOS, modulation of autophagy, and increase in angiogenesis (30).

There are numerous studies demonstrating the role of NO in protecting the heart against $\mathrm{I} / \mathrm{R}$ injury, although some results highlight a controversial role (31). NO plays a positive role by being involved in the mechanisms of protection triggered by cardiac adaptation and ischemic preconditioning, on the other hand it has deleterious effects on the normal heart subjected to I/R alone (32). It is accepted that $\mathrm{H}_{2} \mathrm{~S}$ and $\mathrm{NO}$ cooperatively provide a cardioprotection, although there are fewer studies on the interaction between $\mathrm{H}_{2} \mathrm{~S}$ and $\mathrm{NO}$ in the cardiovascular system. In our study, exogenous NaHS resulted in increased NO levels, and combined L-NAME and NaHS caused an increase in nitrate/nitrite levels, indicating that $\mathrm{H}_{2} \mathrm{~S}$ participates in $\mathrm{NO}$ production. As it is known, $\mathrm{NO}$ and $\mathrm{H}_{2} \mathrm{~S}$ interact with each 
other's synthesizing enzymes, and affect their generation, but the precise mechanism remains unclear (17).

It has been shown that $\mathrm{H}_{2} \mathrm{~S}$ provides cardioprotection against I/R injury by augmenting NO bioavailability via activation of eNOS (33). Congestive heart failure in mice was attenuated by eNOS overexpression, while eNOS deficiency resulted in heart failure and congenital septal defects during cardiac development due to increased apoptotic cardiomyocyte death $(34,35)$. Based on the results of the studies with L-NAME-induced hypertensive rats, Ji et al. (36) and Zhong et al. (37) have suggested that the eNOS/NO pathway was involved in the antihypertensive effects of $\mathrm{H}_{2} \mathrm{~S}$. As confirmed by the significantly increased expression of iNOS mRNA and protein, iNOS is often induced to produce higher $\mathrm{NO}$ in certain pathological conditions involving $\mathrm{I} / \mathrm{R}$ injury $(38,39)$. However, exogenous NaHS administration suppressed iNOS activity and reduced NO content in the plasma and myocardial tissue to improve heart function in a metabolic syndrome model of rats (38). In a mice study by Hua et al. (40), exogenous $\mathrm{H}_{2} \mathrm{~S}$ provided protection against virus-induced myocardial injury through the inhibition of myocardial iNOS mRNA and protein expression. However, studies reporting conflicting results are available in the current literature. For instance, $\mathrm{H}_{2} \mathrm{~S}$ inhibited the activity of eNOS in rat and mouse aortic rings (41), and both exogenous and endogenous $\mathrm{H}_{2} \mathrm{~S}$ reduced NO generation and prevented eNOS activity and transcription (42). Additionally, in the present study, a slight non-significant increase of iNOS expression was observed with L-NAME administration, while the administration of NaHS and PAG in combination with L-NAME resulted in decreased expression. Moreover, NaHS administration caused a decrease in eNOS mRNA expression.

Our biochemical results also indicate that $\mathrm{H}_{2} \mathrm{~S}$ and $\mathrm{NO}$ are required for cardioprotection since the levels of $\mathrm{CK}-\mathrm{MB}$ and $\mathrm{LDH}$ were increased in the L-NAME+PAG group in which $\mathrm{NO}$ and $\mathrm{H}_{2} \mathrm{~S}$ were inhibited, while their levels were decreased in the other groups. Our results are in agreement with those of Yang et al. (38) who have found that exogenous NaHS ameliorated cardiac hypertrophy and myocardial injury in diabetic cardiomyopathy and reduced LDH and CK-MB activities in rats. In addition, another study has shown that CKMB and LDH levels decreased following NaHS administration (4). Reactive oxygen species (ROS) production is accelerated and cellular antioxidants become depleted during myocardial ischemia. $\mathrm{H}_{2} \mathrm{~S}$ is a cytochrome $\mathrm{C}$ oxidase inhibitor and therefore inhibits respiration and thus can decrease the production of ROS and preserve mitochondrial function at low concentrations. In addition, it has been reported that, glutathione peroxidase, an antioxidant enzyme, was increased by NaHS application (4). The GPx, which functions in the detoxification of hydrogen peroxide, increased in the NaHS group of our study, as well as in other studies $(4,38)$. Thus,
$\mathrm{H}_{2} \mathrm{~S}$ may be involved in the activation of endogenous antioxidant mechanism by elevating enzyme levels.

We also found that PAG increased expression of CTH, whereas L-NAME suppressed it. In the PAG group, NO levels were not changed despite increased CTH expression, and this result is in conflict with studies stating that $\mathrm{CTH}$ overexpression promotes NO production (10), and that mice lacking CTH exhibit reduced NO levels (42). It is possible that different $\mathrm{H}_{2} \mathrm{~S} / \mathrm{NO}$ donors/inhibitors and amounts, and different experimental models and parameters may result in conflicting results. Therefore, there is need to examine further the interactions between $\mathrm{H}_{2} \mathrm{~S}$ and $\mathrm{NO}$ in cardioprotection.

In conclusion the results of our study strengthen the evidence that NaHS and L-NAME alone reverse I/R injury induced cardiac performance impairments, while coadministration adversely affected cardiodynamic values as reflected by the biochemical results of tissue markers of cardiac injury. It was also demonstrated that both $\mathrm{H}_{2} \mathrm{~S}$ and $\mathrm{NO}$ increased each other's production. We suggest that $\mathrm{H}_{2} \mathrm{~S}$ and NO cooperated in cardioprotection against $\mathrm{I} / \mathrm{R}$ injury in isolated rat heart. However, there is no doubt that the precise mechanisms underlying these interactions require further studies.

\section{Conflicts of Interest}

The Authors declare that there are no conflicts of interest associated with this work.

\section{Authors' Contributions}

S.U. conceived the work, designed and performed the experiments, analysed the data, and wrote the manuscript. S.T., H.B., D.A., O.H.N., C.D.T., S.U.D., U.O. and E.I.A. designed and performed the experiments and analysed the data. N.Y. and E.G.G. conceived the work, designed and performed the experiments, and critically reviewed and supervised the study.

\section{Acknowledgements}

This work was supported by Scientific Research Projects Coordination Unit of Istanbul University [grant numbers; 31508, 55736 and 47109].

The Authors would like to thank to Prof. Dr. Ismail Meral for providing language help and Aysu Kilic, MSc. for the technical support and writing assistance.

\section{References}

1 Wang R: Two's company, three'sa crowd: $\mathrm{Can}_{2} \mathrm{H}_{2} \mathrm{~S}$ be the third endogenous gaseous transmitter? FASEB J 16(13): 1792-1798, 2002. PMID: 12409322. DOI: 10.1096/fj.02-0211hyp

2 Bełtowski J: Hydrogen sulfide in pharmacology and medicinean update. Pharmacol Rep 67(3): 647-658, 2015. PMID: 25933982. DOI: $10.1016 /$ j.pharep.2015.01.005 
3 Estienne A, Portela VM, Choi Y, Zamberlam G, Boerboom D, Roussel V, Meinsohn M-C, Brännström M, Curry Jr TE and Jo M: The endogenous hydrogen sulfide generating system regulates ovulation. Free Radic Biol Med 138: 43-52, 2019. PMID: 30930295. DOI: 10.1016/j.freeradbiomed.2019.03.028

4 Nicholson CK and Calvert JW: Hydrogen sulfide and ischemiareperfusion injury. Pharmacol Res 62(4): 289-297, 2010. PMID: 20542117. DOI: $10.1016 /$ j.phrs.2010.06.002

5 Shefa U, Yeo SG, Kim M-S, Song IO, Jung J, Jeong NY and Huh Y: Role of gasotransmitters in oxidative stresses, neuroinflammation, and neuronal repair. Biomed Res Int 2017, 2017. PMID: 28386548. DOI: $10.1155 / 2017 / 1689341$

6 Kashfi K: The role of hydrogen sulfide in health and disease. Biochem Pharmacol 149: 1, 2018. PMID: 29501583. DOI: 10.1016/j.bcp.2018.02.030

7 Szabo C: A timeline of hydrogen sulfide $\left(\mathrm{H}_{2} \mathrm{~S}\right)$ research: From environmental toxin to biological mediator. Biochem Pharmacol 149: 5-19, 2018. PMID: 28947277. DOI: 10.1016/j.bcp. 2017.09.010

8 Jin S, Teng X, Xiao L, Xue H, Guo Q, Duan X, Chen Y and Wu Y: Hydrogen sulfide ameliorated 1-name-induced hypertensive heart disease by the akt/enos/no pathway. Exp Biol Med 242(18): 1831-1841, 2017. PMID: 28971696. DOI: 10.1177/ 1535370217732325

9 Mozaffarian D, Benjamin EJ, Go AS, Arnett DK, Blaha MJ, Cushman M, Das SR, De Ferranti S, Després JP and Fullerton HJ: Heart disease and stroke statistics-2016 update a report from the american heart association. Circulation 133(4): e38-e48, 2016. PMID: 26673558. DOI: 10.1161/CIR.0000000000000350

$10 \mathrm{Wu}$ D, Hu Q, Xiong Y, Zhu D, Mao Y and Zhu YZ: Novel $\mathrm{H}_{2} \mathrm{~S}-$ no hybrid molecule (zyz-803) promoted synergistic effects against heart failure. Redox Biol 15: 243-252, 2018. PMID: 29288927. DOI: 10.1016/j.redox.2017.11.020

11 Hu MZ, Zhou B, Mao HY, Sheng Q, Du B, Chen JL, Pang QF and Ji Y: Exogenous hydrogen sulfide postconditioning protects isolated rat hearts from ischemia/reperfusion injury through Sirt1/PGC-1 $\alpha$ signaling pathway. Int Heart J 57(4): 477-482, 2016. PMID: 27357440. DOI: 10.1536/ihj.15-506

12 Kovačić D, Glavnik N, Marinšek M, Zagožen P, Rovan K, Goslar T, Marš T and Podbregar M: Total plasma sulfide in congestive heart failure. J Card Fail 18(7): 541-548, 2012. PMID: 22748487. DOI: 10.1016/j.cardfail.2012.04.011

13 Calvert JW, Elston M, Jha S, Gundewar S, Aragon JP, Grinsfelder DB, Ramachandran A, Elrod JW and Lefer DJ: Hydrogen sulfide therapy attenuates ischemia-induced heart failure via nrf2 and nrf1 signaling. J Am Coll Cardiol 55: A20E186, 2010. DOI: 10.1016/S0735-1097(10)60187-8

14 Hosoki R, Matsuki N and Kimura HJB The possible role of hydrogen sulfide as an endogenous smooth muscle relaxant in synergy with nitric oxide. Biochem Biophys Res Commun 237(3): 527-531, 1997. PMID: 9299397. DOI: 10.1006/bbrc.1997.6878

15 Faro MLL, Fox B, Whatmore JL, Winyard PG and Whiteman M: Hydrogen sulfide and nitric oxide interactions in inflammation. Nitric oxide 41: 38-47, 2014. PMID: 24929214. DOI: $10.1016 /$ j.niox.2014.05.014

16 Whiteman $M$ and Moore PK: Hydrogen sulfide and the vasculature: A novel vasculoprotective entity and regulator of nitric oxide bioavailability? J Cell Mol Med 13(3): 488-507, 2009. PMID: 19374684. DOI: 10.1111/j.1582-4934.2009. 00645.x
17 Wu D, Hu Q and Zhu D: An update on hydrogen sulfide and nitric oxide interactions in the cardiovascular system. Oxid Med Cell Longev 2018: 4579140, 2018. PMID: 30271527. DOI: $10.1155 / 2018 / 4579140$

18 Kondo K, Bhushan S, King AL, Prabhu SD, Hamid T, Koenig S, Murohara T, Predmore BL, Gojon Sr G and Gojon Jr G: $\mathrm{H}_{2} \mathrm{~S}$ protects against pressure overload-induced heart failure via upregulation of endothelial nitric oxide synthase. Circulation 127(10): 1116-1127, 2013. PMID: 23393010. DOI: 10.1161/ CIRCULATIONAHA.112.000855

19 Yong QC, Cheong JL, Hua F, Deng LW, Khoo YM, Lee HS, Perry A, Wood M, Whiteman M and Bian JS: Regulation of heart function by endogenous gaseous mediators-crosstalk between nitric oxide and hydrogen sulfide. Antioxid Redox Signal 14(11): 2081-2091, 2011. PMID: 21194352. DOI: 10.1089/ars.2010.3572

20 Gurel E, Ustunova S, Kapucu A, Yilmazer N, Eerbeek O, Nederlof R, Hollmann MW, Demirci-Tansel C and Zuurbier CJ: Hexokinase cellular trafficking in ischemia-reperfusion and ischemic preconditioning is altered in type i diabetic heart. Mol Biol Rep 40(7): 4153-4160, 2013. PMID: 23652994. DOI: 10.1007/s11033-013-2495-5

21 Livak KJ and Schmittgen TD: Analysis of relative gene expression data using real-time quantitative pcr and the $2^{-\Delta \Delta \mathrm{Ct}}$ method. Methods 25(4): 402-408, 2001. PMID: 11846609. DOI: 10.1006/meth.2001.1262

22 Xie YH, Zhang N, Li LF, Zhang QZ, Xie LJ, Jiang H, Li LP, Hao $\mathrm{N}$ and Zhang JX: Hydrogen sulfide reduces regional myocardial ischemia injury through protection of mitochondrial function. Mol Med Rep 10(4): 1907-1914, 2014. PMID: 25198340. DOI: $10.3892 / \mathrm{mmr} .2014 .2391$

23 Nandi S, Ravindran S and Kurian GA: Role of endogenous hydrogen sulfide in cardiac mitochondrial preservation during ischemia reperfusion injury. Biomed Pharmacother 97: 271-279, 2018. PMID: 29091875. DOI: 10.1016/j.biopha.2017.10.118

24 Luan HF, Zhao ZB, Zhao QH, Zhu P, Xiu MY and Ji Y: Hydrogen sulfide postconditioning protects isolated rat hearts against ischemia and reperfusion injury mediated by the jak2/stat3 survival pathway. Braz J Med Biol Res 45(10): 898-905, 2012. PMID: 22948409. DOI: 10.1590/s0100-879x2012007500090

25 Rossoni G, Sparatore A, Tazzari V, Manfredi B, Soldato PD and Berti F: The hydrogen sulphide-releasing derivative of diclofenac protects against ischaemia-reperfusion injury in the isolated rabbit heart. Br J Pharmacol 153(1): 100-109, 2008. PMID: 17965734. DOI: 10.1038/sj.bjp.0707540

26 Szabó G, Veres G, Radovits T, Gerô D, Módis K, MieselGröschel C, Horkay F, Karck M and Szabó C: Cardioprotective effects of hydrogen sulfide. Nitric Oxide 25(2): 201-210, 2011. PMID: 21094267. DOI: 10.1016/j.niox.2010.11.001

27 Caliendo G, Cirino G, Santagada V and Wallace JL: Synthesis and biological effects of hydrogen sulfide $\left(\mathrm{H}_{2} \mathrm{~S}\right)$ : Development of $\mathrm{H}_{2} \mathrm{~S}$-releasing drugs as pharmaceuticals. J Med Chem 53(17): 6275-6286, 2010. PMID: 20462257. DOI: 10.1021/jm901638j

28 Johansen D, Ytrehus K and Baxter GF: Exogenous hydrogen sulfide $\left(\mathrm{H}_{2} \mathrm{~S}\right)$ protects against regional myocardial ischemiareperfusion injury. Basic Res Cardiol 101(1): 53-60, 2006. PMID: 16328106. DOI: 10.1007/s00395-005-0569-9

29 Hussain A, Maddock H, Al-Rajaibi H and Carson RJ: Effects of hydrogen sulphide on the isolated perfused rat heart. Sultan Qaboos Univ Med J 11(2): 236, 2011. PMID: 21969896. 
30 Zhang L, Wang Y, Li Y, Li L, Xu S, Feng X and Liu S: Hydrogen sulphide $\left(\mathrm{H}_{2} \mathrm{~S}\right)$-releasing compounds: Therapeutic potential in cardiovascular diseases. Front Pharmacol 9: 1066, 2018. PMID: 30298008. DOI: 10.3389/fphar.2018.01066

31 Matejikova J, Kucharska J, Pancza D and Ravingerova T: The effect of antioxidant treatment and nos inhibition on the incidence of ischemia-induced arrhythmias in the diabetic rat heart. Physiol Res 57(Suppl 2): S55-S60, 2008. PMID: 18373392.

32 Andelova E, Bartekova M, Pancza D, Styk J and Ravingerová $\mathrm{T}$ : The role of no in ischemia/reperfusion injury in isolated rat heart. Gen Physiol Biophys 24(4): 411, 2005. PMID: 16474186.

33 Shen Y, Shen Z, Luo S, Guo W and Zhu YZ: The cardioprotective effects of hydrogen sulfide in heart diseases: From molecular mechanisms to therapeutic potential. Oxid Med Cell Longev 2015: 925167, 2015. PMID: 26078822. DOI: $10.1155 / 2015 / 925167$

34 Jones SP, Greer JJM, van Haperen R, Duncker DJ, de Crom R and Lefer DJ: Endothelial nitric oxide synthase overexpression attenuates congestive heart failure in mice. Proc Natl Acad Sci USA 100(8): 4891-4896, 2003. PMID: 12676984. DOI: 10.1073/ pnas.0837428100

35 Feng Q, Song W, Lu X, Hamilton JA, Lei M, Peng T and Yee S-P: Development of heart failure and congenital septal defects in mice lacking endothelial nitric oxide synthase. Circulation 106(7): 873-879, 2002. PMID: 12176963. DOI: 10.1161/ 01.cir.0000024114.82981.ea

36 Ji W, Liu S, Dai J, Yang T, Jiang X, Duan X and Wu Y: Hydrogen sulfide defends against the cardiovascular risk of nwnitro-l-argininemethyl ester-induced hypertension in rats via the nitric oxide/endothelial nitric oxide synthase pathway. Chin Med J (Engl) 127(21): 3751-3757, 2014. PMID: 25382331. DOI: 10.3760/cma.j.issn.0366-6999.20141573

37 Zhong G, Chen F, Cheng Y, Tang C and Du J: The role of hydrogen sulfide generation in the pathogenesis of hypertension in rats induced by inhibition of nitric oxide synthase. J Hypertens 21(10): 1879-1885, 2003. PMID: 14508194. DOI: 10.1097/00004872-200310000-00015
38 Yang R, Jia Q, Liu XF, Wang YY and Ma SF: Effects of hydrogen sulfide on inducible nitric oxide synthase activity and expression of cardiomyocytes in diabetic rats. Mol Med Rep 16(4): 5277-5284, 2017. PMID: 28849194. DOI: 10.3892/ mmr.2017.7247

39 Soliman H, Craig GP, Nagareddy P, Yuen VG, Lin G, Kumar U, McNeill JH and MacLeod KM: Role of inducible nitric oxide synthase in induction of rhoa expression in hearts from diabetic rats. Cardiovasc Res 79(2): 322-330, 2008. PMID: 18411229. DOI: $10.1093 / \mathrm{cvr} / \mathrm{cvn} 095$

40 Hua W, Chen Q, Gong F, Xie C, Zhou S and Gao L: Cardioprotection of $\mathrm{H}_{2} \mathrm{~S}$ by downregulating inos and upregulating ho-1 expression in mice with cvb3-induced myocarditis. Life Sci 93(24): 949-954, 2013. PMID: 24140888. DOI: $10.1016 / j . l f s .2013 .10 .007$

41 Kubo S, Doe I, Kurokawa Y, Nishikawa H and Kawabata A: Direct inhibition of endothelial nitric oxide synthase by hydrogen sulfide: Contribution to dual modulation of vascular tension. Toxicology 232(1-2): 138-146, 2007. PMID: 17276573. DOI: $10.1016 /$ j.tox.2006.12.023

42 King AL, Polhemus DJ, Bhushan S, Otsuka H, Kondo K, Nicholson CK, Bradley JM, Islam KN, Calvert JW and Tao YX: Hydrogen sulfide cytoprotective signaling is endothelial nitric oxide synthase-nitric oxide dependent. Proc Natl Acad Sci USA 111(8): 3182-3187, 2014. PMID: 24516168. DOI: 10.1073/pnas. 1321871111

Received April 28, 2020

Revised May 11, 2020

Accepted May 12, 2020 